\title{
Mother Tongue Injustice: Reflections on the Kenyan Justice System
}

\author{
Henry Simiyu Nandelenga (Ph.D.) \\ Department of English, Literature \& Journalism, Kibabii University, Kenya, \\ P. O. Box 1699-50200, Bungoma - Kenya \\ E-mail:khwamu@gmail.com
}

\begin{abstract}
The inalienable right to one's mother tongue has long been acknowledged universally. This was first captured by the UN's 'Universal Declaration of Human Rights' as early as 1948 and recently reinforced through the 'Declaration on the Rights of Indigenous People' in 2006. The constitution of Kenya 2010, in The Bill of Rights (BR), reiterates this position by stating that the rights and fundamental freedoms belong to each individual and are not granted by the state. Mother tongue is one of the Human Rights. In essence, the constitution is expected to provide a basis upon which mother tongue can play a central role in the legal and judicial system of the country. However, mother tongue language remains on the periphery as the language of the law not to mention its subordinate role both as a legal language and the language of the administration of justice. This paper examines the current low status assumed by mother tongue in the Kenyan context within the Forensic Linguistics perspective. It is argued that there is an attempt at forced assimilation of mother tongue language to the dominant English language in our justice system. This process is at the heart of human rights violations as envisaged in the constitutional provisions on equality and freedom against discrimination as per article 27(4) of the Bill of Rights. The right to use of one's mother tongue in the legal process is a fundamental pillar of equality and freedom against discrimination. It ensures that every person is equal before the law and has the right to equal protection and benefit of the law. The state players, therefore, have an obligation to protect the mother language through enforceable legislation as contemplated by the constitution of Kenya Article 7(3). The same constitution must be re-examined and amended to put mother tongue at the core of judicial administration and legal practice in the country.
\end{abstract}

Keywords: Mother tongue, injustice, legal, constitution, forensic linguistics.

DOI: $10.7176 / \mathrm{JLPG} / 118-13$

Publication date: February $28^{\text {th }} 2022$

\subsection{Introduction}

A person's mother language is part and parcel of one's individuality. The right to express oneself in the mother tongue is a core principle in the legal systems across the world. Indeed, this right is a constitutional right that is inalienable neither by state nor state agencies and organs. On this basis, it is assumed that the rights and fundamental freedoms enjoyed by citizens are not granted by state but are inalienable human rights whose aim is to preserve human dignity and promote social justice. Among the rights and fundamental freedoms is the right to the use of our mother tongue in all spheres of life including in the legal process. The right to the use of mother tongue was long recognized as fundamental pillar in the protection of civil and personal rights by the United Nations, as espoused in the 'Universal Declaration of Human Rights' of 1948. Yet mother language has often had a back seat in social and official discourse in the contemporary legal practice in many countries in spite of this Declaration.

Marginalized and minority groups have had their mother language rights violated by state organs with impunity especially during conquest with forced linguistic assimilation ensuing. It is in the light of this scenario that the UN General Assembly adopted the 'Declaration on the Rights of Indigenous People' in 2006 to address this anomaly. However, resistance to this right for indigenous people in former colonial countries remains an issue. In these countries, various excuses have been used to sabotage any effort meant to put mother language at the center of social interaction in the public and private domains. Equally, there are clear inconsistencies in UN's own policy on mother tongue and the people's right to use and promote their mother language. This is apparent in the refusal by the General Assembly to officially adopt the Universal Declaration of Linguistic Rights (The Barcelona Declaration) of 1996 whose central objective was to ensure protection of linguistic rights of all people especially the minority and marginalized communities.

In the same vein, Kenya's 2010 constitution (National Council for Law Reporting, 2013; hereafter, NCLR) provides for the protection and promotion of local languages and diversity of culture for which language is a key component. It states that the state, among other things, shall endeavour to promote and protect the diversity of the languages of the people of Kenya and also, promote the development and use of indigenous languages. However, in actual implementation of the constitutional provisions, there are glaring gaps and contradictions. State organs and persons charged with actualization of these provisions into law (parliament) and enforcement of 
the same (Attorney General and the Judiciary), have been a major obstacle. No tangible laws have been enacted to ensure the rights of Kenyans to the use of their mother language. Specifically, the justice system (based on archaic British tradition) does not provide to the litigants and seekers of justice, the right to the use of their mother languages in judicial matters.

Mother tongue language in the legal and justice system has been subordinated to the dominant English language that is currently 'a de facto language of the law and justice system' in Kenya. It is instructive that the Constitution of Kenya has never been translated into any single indigenous language, not to mention Kiswahili, which is a mother tongue and a national language in the country. The subordinate role played by the mother tongues in Kenyan justice system has done injustice to the users of these languages. In essence, the very institution mandated to uphold and enforce the constitution, has abdicated its role, inadvertently subverting justice to Kenyans. Whatever alternatives there are to mother tongue through translation or use of the national language (Kiswahili), do not guarantee justice to the concerned parties. Words, and by extension language, has meanings and not all word meanings are translatable; few have semantic equivalents in other cultures and by extension, language. Interpreting or translating mother tongue in the 'official courtroom language' does injustice to the users of mother tongue because of the system specificity of legal terminology across languages (De Groot \& van Laer, 2006:65).

Language is a critical factor in the legal system. It is important that Kenyans have access to the language of their choice considering the pertinent role played by language in the judicial and legal processes. As observed by a preeminent forensic linguist and I quote; "the law is an overwhelmingly linguistic institution. Laws are coded in language and concepts that are used to construct the law are accessible only through language", (Gibbons, 2005:1). Cases are won and lost purely on the basis of language semantics and not on any substantive evidence in courtroom discourse. Often, innocent litigants are condemned to jail terms and death while hardcore criminals are set free largely on linguistic evidence. The language of the court can both empower and enfeeble those seeking justice. In the Kenyan justice system, denial of mother tongue use is considered a norm but it inflicts undue injustice to Kenyans who lack mastery of the official judicial language; the Common Law English. There is need to address this anomaly at all levels of justice administration and legal practice for the protection of the lay justice seekers.

The legal systems across the world can be categorized into four: the court of laws, the court system, the police service and the prisons forming the judicial system. Other subsidiary organs such the probation services that may be subordinate to any of the above are part of the legal system (Gibbons, 2005:2). Besides, there may be regulatory bodies that are paralegal in nature having oversight roles over the above largely through tribunals. Language of the law is characteristic of these bodies especially in criminal law in court proceeding where its impact is most visible. Mother tongue is relevant in these institutions in the sense that law evolved prior to the emergence of writing in the regulatory system. Oral legal systems have been around for generations and persist today in some cultures as 'Traditional Law'. It is worth noting that formal legal systems such as a Sharia, Roman Law and Common Law, do exist alongside the traditional law in many countries including Kenya where mother tongue plays a central role.

The distinctive feature of the Roman law is that there is no presumption of innocence, its proceedings are inquisitorial and the judge acts as both decision maker and investigator. The defence is weaker in this system. This is used in English language legal system in commissions of inquiry, tribunals or Grand Jury (USA). On the other hand, the Common Law, often referred to as Anglo-American Law, is adversarial in nature. It is common in countries where English is the language of the law. In criminal law, there is the presumption of innocence until proved guilty; the burden of proof is on the prosecution. In civil matters, judgement is made on the basis of probabilities or 'preponderance of evidence' (Gibbons, 2005: 6). A key characteristic of the Common Law is the adversarial proceedings dominated by ritualized linguistic battle between the prosecutor and defendant. In this system, the recorded judgements (precedents) form the basis for subsequent judgement by another judge (judge made law) when making a decision on the same point of law. In jury trial, the judge advises the jury on the law but the jury decides on guilty or liability while the judge decides the penalty/damage. Where there is no jury, the judge decides both the verdict and penalty. The language of jury instructions has often been portrayed as the source of miscarriage of justice due to its opaque nature (Tiersma \& Solan, 2002).

\section{The Language of the Legal System}

The law is a crucial regulator of our behaviour that ensures orderly relations among ourselves and the environment we inhabit (Tiersma, 2001). It is the manager of our daily lives based on the value system we have inculcated conventionally by imposing upon us both rights and obligations. Language is an indispensable tool in the entire legal process right from legislation, interpretation, administration and enforcement of the law. According to Mattila (2006: 6) "Law is necessarily bound to language (notably in matters of legal interpretation), and in that sense legal language has existed as long as the law". The legal processes, by large, take place via language whether it is a court case, police investigation or prison administration. Most legal documents are 
essentially language documents. On the other hand, as pointed out by Olsson (2016), it is rare that a crime is committed without some language evidence, more so, crime is created by language (Shuy, 2005). In a nutshell, language pervades all spheres of our lives just like the laws they encode hence our mother tongue is central in legal administration.

However, legal language though based on ordinary language, is different in the sense that it is a language for special purposes characterized as a technical language or 'technolect' (Mattila, 2006:3). The language of the law may be divided into two; the codified written language of legislation and other documents that are largely monologic and the spoken interactive dynamic language of the legal process (courtroom language). Legal written texts are three (Tiersma, 1999; Gibbons, 2005); the operative, expository and persuasive documents. The former has all the hallmarks of legal language with the latter two being less formulaic and legalistic. Modern legal systems have their genesis in oral tradition conventionally referred to as Customary Law. Overt codification of the legal language makes for absence of some concept such as 'intention' in customary law. It is argued that what orate societies lack is a legal register because legal disputes are handled in everyday language and not some specialized legal jargon.

On the contrary to the ordinary language, a chief characteristic of the legal language is its opaqueness and aloofness (de-contextualized) to the extent that only the legal fraternity may understand it. Typical syntactic features that characterize the legal genre includes; the binomial expressions such as 'by and with the advice and consent', complex prepositions such as 'in the course of' and long, complex, multi-clause sentences with syntactic matching in the subordinate clauses (Coulthard \& Johnson, 2007:39). Indeed, Coulthard and Johnson (2010:35-36) point out that the term legal languages has become synonymous with a language that is full of grammatical complexity, sparsely punctuated, over-lexicalized and opaque written texts. They further observe that "legal language has a reputation for archaisms and convoluted syntax... it is simply [sic] impenetrable".

Bhatia (1993: 101) in the same vein puts it that legal written English "... has acquired a certain degree of notoriety rarely equalled by any other variety of English. It has long been criticized for its obscure expressions and circumlocutions, long-winded involved constructions and tortuous syntax, apparently meaningless repetitions and archaisms". The legal language is thus portrayed as a frightening phenomenon imposed on a society. Coulthard and Johnson (2010:1) concede thus "...we know that the legal world is context-rich. It is peopled by a hierarchical mini-nation of judges, lawyers, police and law-enforcement officers and then the common man and woman, who walk, like Adam and Eve, unknowing, through this strange world". The above quotation aptly sums up the agony of lay litigants in the judicial process that seems too alien to afford them any reprieve as they seek justice due to the inaccessible and opaque legal language.

However, why should this be the case when legal language is meant for communicating issues that are pertinent in securing and promoting justice? For drafters of legal documents, according to Bhatia (1993:102) their justification is based on the view that their profession demands that they "convert legal intentions into unambiguous prose, constructions whose main purpose is to bring precision, clarity, unambiguity and allinclusiveness". But the author contrasts this by asserting that "...it may be a ploy to promote solidarity between members of the specialist community and to keep non-specialists at a respectable distance". Similarly, the author is of the view that "the legal drafter is in an unenviable position, striving to use language to do justice to the intent of Parliament and to facilitate comprehension of the unfolding text for ordinary readership". The author stresses the fact that drafter must also "...protect the intended interpretation against uncooperative readings by skillful lawyers" (Bhatia, 1993: 103).

According to Halliday (1985) though, the legal language is largely the way it is based on the functions it is meant to do. For example, in legal settings such as ritual openings of the police caution (the Miranda warnings), beginnings of an interview or the reading of the indictments, use formulaic expressions signaling the start of a formal legal process, among others, are the norm. It is apparent that such language is incomprehensible and thus distances and disadvantages the lay participants. But observers have argued aptly that such language use in the legal fraternity is meant to preserve professional monopoly and so control legal proceedings to the advantage of the counsels/advocates (the bar) and the judges/magistrates (the bench) (Maley, 1994:12).

In a courtroom discourse, language users construct a social and physical world that is pragmatically related to the social-cultural and physical contexts they inhabit (Gibbons, 2005). The world view of participants is based on some shared knowledge and different perspectives of their social and material world. If indeed we view our world through our language, then this knowledge consists of our communicative ability; the communicative competence. As argued by majority linguists, native speaker competence is all that is required in adequate language use. Legal documents or process coined in a language other than mother language inevitably lacks this knowledge. This is the injustice that those seeking justice suffer when they cannot construct their world view of the material events that are the subject of court proceedings or trial. They can only defend or prosecute their case fairly in their mother tongue which is not available to them.

The greatest pursuit of the legal language is precision, and like any other profession, it has developed specialized vocabulary and special way of conceiving and constructing the world and expressing its 
understanding. Wording of legislation must have a single clear meaning as basis for interpretation and imposition of the law; the 'plain meaning rule' in the legal school of 'textualism'. De-contextualization of written texts has some consequences; high level of autonomy in legal texts is critical in drafting and interpretation of legislation. In Linguistics however, language is not a simple unambiguous means of communication. It is not just about the legal 'jargon' per se but the legal view of the social and physical whose 'legal' meaning is at variance with everyday usage. While technical terms are considered 'shorthand' in making language efficient and compact, it often leads to lack of clarity. Often, it may portray a different sociocultural role that is different in intent (Gibbons, 2005:14). There is knowledge gap between lawyers and non-lawyers; legal jargon, referring to legal concepts, require technical language because it is not part of everyday knowledge, yet majority of Kenyans lack this knowledge.

Another characteristic of legal English language is the use archaic deictics which lawyers prefer for having clearer and less ambiguous reference. Yet these only serve to enhance interpersonal power and legal conservatism. The history of Common Law has given us a number Latin and Norman French archaism such as; affidavit, ex parte, caveat, in camera, order of certiorari (Latin) and lien, larches, quash, void, judge (NF). Lawyers operate within different conceptual and discoursal 'frame' such that they construct, discuss and present events in a manner that differs and is unintelligible to non-lawyers (Stygall, 1994). Such in-group language is both inclusive and exclusive. In the legal system, there is the 'two audience dilemma' arising from the legal language in the judicial system, that is; language appropriate to the lay witness audience on one hand and to the specialist legal audience, on the other. Specialist English terms such as committal, deforcement, felon, plaintiff, homicide and assault have quite different legal sense from everyday usage, i.e. the latter two may not involve physical contact in the legal semantics.

The pursuit for precision is driven by the desire for legal documents to define and control human behaviour in unambiguous manner' (Gibbons, 2005). However, it is noteworth that the pursuit of precision when combined with extreme conservatism and archaism, leads to language that is arcane and unintelligible to non-lawyers, producing what observers call 'obfuscation' and Melinkoff (1963) calls it 'pompous'. Difficulties encountered in courtroom discourse may, therefore, emanate from two sources; non-lawyers not understanding the legal language and the lawyers not understanding the people who lack mastery of the legal language. It is generally agreed that although the English Law is communicated largely in English, most speakers of the English language are excluded from semiotic group of the law, (Jackson, 1990: 87). This is mainly because they cannot grasp the register of the language in which the law is coded.

One of the glaring injustices resulting from the unintelligible legal language is the fact that the Common Law presumes that 'ignorance of the law is no defence'. It is difficult to challenge what you do not understand in a courtroom. In essence, legal language must be intelligible to the people affected by it so that they can understand and protect their own legal and contract rights not to mention their meaningful participation in legal proceedings. Criticism against incomprehensibility of legal language has a long tradition reported as early as 1893 by Dickens in 'Bleak House' and many satires abound. As pointed out by (Gibbons, 2005:199) 'without public understanding of the law, it becomes an avenue for oppression rather than order, for injustice rather than justice'. The legal language is said to be unintelligible to ordinary readers and barely intelligible to lawyers. Renton (1975) concludes that even lawyers and judges find legal drafting an impenetrable barrier to understanding it for being highly convoluted.

In view of these difficulties, the 'Plain Language Movement' emerged with a view to making legal language accessible and intelligible to its consumers. Its genesis is Gowers' (1948) 'Plain Words' transforming itself into 'Plain English Campaign' in Britain whose sole aim was to push for plain English law. The campaign has spread to the USA and Australia among others. In Britain, the movement led to changes in which many forms, documents and procedural wordings have been substituted with clearer equivalents. For instance, most arcane legal terms have been replaced such as 'plaintiff' now referred to as 'claimant', 'a pleading' now 'a statement of case' among others. Latin legal terms have been replaced, for example, 'ex parte, inter partes, in camera, and sub poena' are now 'with notice, without notice, in private and summons'.

In the Law of Tort (Contract) the difficulty of legal language is apparent in purchase contracts, insurance policies and financial credit contracts, among others. Plain Language Practitioners argue for improvements in the language of contract that is meant to be read by a lay audience. For example, in 'covenants and conditions' of purchase agreement for car reported by Gibbons (2005:183), there is a clear difference in readability/intelligibility of the agreement between the legalistic original and plain language version as shown herewith;

The buyer further promises to pay the holder hereof a delinquency and collection charge for default in the payment of any instalments above recited, where such default has continued for a period of ten days, such charge not to exceed five percent of the instalments in default or the sum of five dollars, whichever is the lesser.

Compare with: 
You also promise to pay a late fee if your payment is more than ten days overdue. The late fee will be five percent of the amount overdue or five dollars whichever is less.

It is apparent that the two forms of contract give priority to two different audiences; the older legalese form prioritizes the legal audience while the newer plain language version, targets the client lay audience. The underlying motive in plain language movement is to remove superfluous details and also "register shift, from more written to more spoken, from more technical to more everyday conversational, from more formal to more informal" (Gibbons, 2005: 186).

In the Kenyan justice system, poor communication largely arises because of the use of legal language involving the police who are hardly conversant with the legal genre. The risk is that in the Common Law tradition of the Kenyan courts, much of the power to prosecute is vested in the police officer in most local Magistrate and District courts. In cases involving minor offences, the police present evidence that a suspect is guilty which is accepted without further investigation of argument. In essence, the main concern in such courts is sentencing rather than decisions about guilt or innocence. In Kenya, like other Common Law countries, the police interviews or interrogations contain some 'scripted' cautions informing interviewees of their legal rights or obligations during the interviews or interrogations. Nowhere is there mention of their right to be informed of the charge or to be interviewed in their mother language.

Such scripted cautions may include the fact that a person may have the right to silence, right to legal representation, right to decline being recorded, right not to do anything unless if he/she wishes to do so, right not to be audio-taped, right to be informed of the purpose of interrogation or arrest, among others. Generally, there is no mention of the right to use one's mother tongue and to decline responding to questions not framed in one's mother tongue or the right to an interpreter. It is at this point that injustice takes root in the entire legal process with no recourse to an alternative avenue in which mother language may be used by the accused. In a typical Kenyan court, the judge simply asks the litigants if they understand English or not. In a few cases, they may ask if the litigants understand English or Kiswahili with no provision for any other mother languages spoken across Kenya.

\subsection{The Kenyan Constitution and Mother Tongue}

The role of mother language and other indigenous languages is considered a pillar for the linguistic diversity of the country according to the Constitution of Kenyan. To this end, the state is obliged to protect and promote this diversity while developing and promoting its usage as set out in Article 7 (3) of the Constitution of Kenya, 2010 (NCLR, 2013). Similarly, Kiswahili, one of the indigenous and mother languages of the coastal Kenyan communities, is recognized as both the National Language and one of the Official Languages of the Republic of Kenya. This is significant because it gives recognition to a local language the status that is required. Article 10 (2b) on national values and principles of governance makes it explicit that human dignity, equity, social justice, inclusiveness, equality, human rights, non-discrimination and protection of the marginalized shall be honoured in which mother tongue is arguably a key component. Mother tongue is part of our human dignity, equality and equity before the law and a manifestation of social justice and therefore, any denial of the same is a violation of this dignity, equality and social injustice.

Chapter Four of the constitution focuses on The Bill of Rights and Article 19 (2) asserts that the purpose in the recognition and protection of human rights and fundamental freedoms is to preserve the dignity of individuals and communities and to promote social justice among others. In the application of the Bill of Rights, Article $20(1 \& 2)$ states that the Bill of Rights applies to all law and binds all state organs and persons, and that every person shall enjoy the rights and fundamental freedoms to the greatest extent consistent with the nature of the right or fundamental freedom. Similarly, in the same article clause 5b, "the state is obliged to allocate resources giving priority to the widest possible enjoyment of the right or fundamental freedom having regard to prevailing circumstances, including the vulnerability of particular groups or individuals". Mother tongue is not just part of our humanity; it is a communal asset and its usage, is in fact, an assertion of community dignity. However, in practice, state organs such as the courts, have perpetually violated these provisions in not ensuring individuals are free to use their mother tongue in the justice system. Similarly, the national government has routinely failed to allocate resources for full implementation of these provisions. By 2022, mother tongue use is not guaranteed in the judicial system especially the courts.

In the implementation of these rights, Article 21 provides that it is a fundamental duty of the state and every state organ to observe, respect, protect, promote and fulfill the rights and fundamental freedoms in the Bill of Rights by taking legislative, policy and other measures, including the setting of standards, to achieve the progressive realization of these rights. Furthermore, all state organs and public officers have the duty to address the needs of vulnerable groups within society, including but not limited to members of minority or marginalized communities, and members of particular ethnic, religious or cultural communities. Finally, the State shall enact and implement legislation to fulfill its international obligations in respect of human rights and fundamental freedoms. In this regard, parliament has failed to enact water tight laws that guarantee observance of linguistic 
rights in our justice system in which mother tongue has no visible role and its use frowned upon by those who wield the linguistic power.

On the enforcement of the Bill of Rights in Article 22, the constitution provides every person the right to institute court proceedings whenever a right or fundamental freedom in the Bill of Rights has been denied, violated, infringed or is threatened. The constitution also gives authority to the courts to uphold and enforce the Bill of Rights including those relating to language. In this regard, the High Court has jurisdiction, in accordance with Article 165, to hear and determine applications for redress of a denial, violation or infringement of, or threat to a right or fundamental freedom in the Bill of Rights. Parliament is expected to enact legislation to give original jurisdiction in appropriate cases to subordinate courts to hear and determine applications for redress of any violation of these fundamental freedoms in the Bill of Rights. In addition, in any proceedings brought under Article 22, a court may grant appropriate relief, including a declaration of rights, an injunction, a conservatory order, a declaration of invalidity of any law that denies, violates, infringes, or threatens a right or fundamental freedom in the Bill of Rights and is not justified under Article 24 (that provides for reasonable limitation), an order for compensation and judicial review. Both the courts and parliament are meant to give force to these provisions by enacting laws on mother language that are enforceable, yet continued denial of mother tongue usage, particularly in the courts, remains the norm.

Article 27 provides for equality and freedom from discrimination. Specifically, clause 1 and 2 asserts that every person is equal before the law and has the right to equal protection and equal benefit of the law. Such equality includes the full and equal enjoyment of all rights and fundamental freedoms. The article require that the state shall not discriminate directly or indirectly against any person on any ground, among others; race, ethnic or social origin, culture and language. To ensure compliance to this provision, clause 6 and 7 of the same Article provides that the state shall take legislative and other measures, including affirmative action programmes and policies designed to redress any disadvantage suffered by individuals or groups because of past discrimination and such measure shall adequately provide for any benefits to be on the basis of genuine need. Article 28 on human dignity states that every person has inherent dignity and the right to have that dignity respected and protected. When mother language is not used in the justice and legal process, it is a violation of fundamental freedoms and a form of discrimination contrary to Articles 27 and 28. Language is part of our culture, manifests our ethnicity and race, hence subordination of mother tongue is more than mere discrimination

Similarly, on language and culture, Article $44(1 \& 2)$ states that every person has the right to use the language and to participate in the cultural life of his/her choice. A person belonging to a cultural or linguistic community has the right, with other members of that community, to enjoy his/her culture and use his/her language or to form, join and maintain cultural and linguistic associations and other organs of civil society. Clause $2 \mathrm{a}$ is very specific on a person's right to use his/her language. Article 48 on access to justice, provides that the state shall ensure access to justice for all persons and, if any fee is required, it shall be reasonable and shall not impede access to justice. The rights of arrested persons are protected by Article 49 of the constitution. Clause 1 states that Kenyans have a right to be informed promptly, in a language that the person understands, of the reason for the arrest, the right to remain silent and the consequences of not remaining silent, among other information. However, the right to use mother tongue is routinely violated in the justice system and access to justice is limited by the bureaucratic legalese language of the courts that is hardly comprehensible to persons seeking justice. People's choice in using their mother tongue is curtailed when English is the de facto language of the courts.

In addition, Article 50 on fair hearing provides that every accused person has the right to a fair trial, which includes the right to be presumed innocent until the contrary is proved, to be informed of the charge, with sufficient detail to answer it, to have adequate time and facilities to prepare a defence. In addition, the person has the right to choose to remain silent, and not to testify during the proceedings, to have the assistance of an interpreter without payment if the accused person cannot understand the language at the trial. Clause 3 and 4 of the same Article provides that if this Article (50) requires information to be given to a person, the information shall be given in a language that the person understands and evidence obtained in a manner that violates any right or fundamental freedom in the Bill of Rights shall be excluded if the admission of that evidence would render the trial unfair, or would be detrimental to the administration of justice. To this end, there can never be a fair trial if one is not allowed to use the language he or she understands, nor access to an advocate who understands their mother language when they are not competent in legal English. Besides, evidence given in a language other than the mother language is a travesty of justice when its interpretation is at variance with that of mother tongue.

Article $54(1 \mathrm{a} \& d)$ on disabilities states that, among other provisions, a person with any disability is entitled to be treated with dignity and respect and to be addressed and referred to in a manner that is not demeaning and to use sign language, Braille or other appropriate means of communication. Article 56 (d) on minorities and marginalized groups, the constitution states that the State shall put in place affirmative action programmes designed to ensure that minorities and marginalized groups develop their cultural values, languages and practices. 
Article 120 provides for the official languages of Parliament. It states that the official languages of Parliament shall be Kiswahili, English and Kenyan Sign Language (KSL). The business of Parliament may be conducted in English, Kiswahili and Kenyan Sign Language. Yet Article 259 (2) on construing of the constitution argues that if there is a conflict between different language versions of this Constitution, the English language version prevails. This is a clear contradiction in negating mother tongue usage by elevating English to the status of a 'constitutional' language!

There are glaring injustices pertaining to Articles 54, 56 and 120. There are contradictions inherent in the constitution that have given state organs and the judicial system, in particular, an open cheque to subordinate Mother languages in the administration of justice. The deaf who need sign language do not have such services while minorities who often have little education in English, the language of the courts, have no redress and there is no affirmative action in the justice system to remedy this injustice. Largely because mother languages of the country are not recognized constitutionally for use in parliament, it is evident that they cannot be accorded any role outside parliament, for instance, the courts. If English must prevail in case of any conflict in the interpretation of the constitution, it gives license to the marginalization of mother languages, an injustice that pervades our justice system because they virtually have no legal backing.

\subsection{Courtroom Interaction as diagnostic of Mother Tongue Injustice}

Courtroom interaction provides a clear picture of how linguistic legal power and privilege can be abused by those who 'own' this commodity. Mastery of the legal language or jargon (typically legal English) by the bar and the bench ensures that power is concentrated among these privileged groups while those facing the law with no mastery of the legal jargon are perpetually powerless. Linguistic disadvantage before the law is a theme in many Forensic Linguistics books and Law Reviews all over the world largely because in courtroom interaction, cases are lost and won on the basis of linguistic prowess of the litigants. The power asymmetry buttressed in our legal system is aptly summed by an Indian Dalit who observes that 'we have not the slightest faith in the legal or judicial process. We know the law is for the big people' (Gibbons, 2005:200). Power in the courtroom includes individual's power over others in interactions and social power based on social hierarchy and organizational structure of the judicial system.

Power and solidarity are manifested among the 'educated judicial and legal fraternity'. The use of specialist language is the coveted marker of membership of this exclusive specialist group. Language behaviour most clearly manifests power relations; in the courtroom, power and authority are typically exercised through language. Gibbons (2005:75) observes that the judicial system is arguably the most directly powerful institution in societies subject to 'the rule of the law'. The legislature conceded power to the judiciary for orderly working of society. Judges have the power to interpret the law then decide whether to enforce them or not. Indeed, it has been observed that the law is a bureaucracy and that much of the power is a manifestation of organizational hierarchy and the legal register is a 'hierarchical, authoritarian, monologic use of language', (Goodrich, 1987:3). In Kenya's Common Law trial, the legal process is 'adversarial' in which the prosecution and defence take on opposing positions, a kind of linguistic 'warfare'. In cross examination, the two minds involve both overt and covert conflict. Often, the lawyers initiate and control the process linguistically depicting a typical power asymmetry at play in the judicial process in which non-experts are at the mercy of the legal fraternity.

Over-elaboration (hypercorrect register) is often an aspect in courtroom discourse in which linguistically formal rather than informal terminology is preferred such as 'solicit' for 'ask', 'proceed' for 'go', 'effect' for 'make', 'decamp' for 'leave the scene', 'disturbance' for 'fight', 'affirmative' for 'yes', among others. This adjusts speech to a higher register and stakes claim to power and authority. Studies on linguistic indicators of power show that people who are less powerful in society may reflect their status in their speech behaviours and consequently be less convincing as witnesses. According to Gibbons $(2005: 88)$ if they are the accused, they are less likely to get justice. In address forms, there are most obvious markers of power and prestige besides portraying the impersonal nature of the justice system. Judges are rarely referred to by name, instead; 'Your honour, Your Lordship, Your Worship', and use of the third person of the verb, i.e. Your Honour please. Often, the impersonal nature of the courts is clear; the court, the bench judge treated as impartial third party thereby imparting authority to his statements and decisions. Even when their names are used, their powerful honorifics are included.

Turn taking in courtroom linguistic discourse manifests asymmetrical power relations. The judge or magistrate, the most powerful, may often speak and interrupt at will in a strange language. The most powerless, the witnesses and defendants observes, can be punished or jailed if they speak at will or simply for laughing. Witnesses are given a 'turn' to speak but have no control over when to and what to say and more so, in what language. While lawyers and counsels often interrupt witnesses, the latter are not expected to even on matters linguistic. In police interviews, the control of the process is with the interviewing officer who has absolute power over the topic, turns and the language to use. Often questioning is for purposes of confirming an already made version of event that the questioner has in mind. Typically, lawyers use questioning to supply a particular 
prepared account of event to the judge. Jacquemet (1996), reports that courtroom questioning techniques are primarily used to win cases but not to help courts discover facts. Police questioning is meant to obtain evidence that can lead to successful conviction. Pursuit of proof overrides pursuit of truth in which case coercive interrogation to confirm police version of the event (in the form of a confession) is the desired end. This is typical of the Kenyan scenario.

Considering that it is the powerful who wield the linguistic power in the interactions, it is lawyers, police officers and prosecutors who mostly ask questions. Power asymmetries may affect the right to ask questions, the obligation to answer them and the content of the less powerful person's response. Yet the form in which the question is put has great influence on the quality of the answer ensuring control of information and compliance of the person being questioned. This is true of questions in which there is a veiled presupposition coined in the legal language. The reasoning behind this is that by controlling what witness say (through some unintelligible language), lawyers/prosecutors will control what the judges think. A common strategy by counsels on 'hostile' witnesses is to attempt to upset, unsettle, confuse, confound or intimidate witnesses linguistically via barrage of questioning. Politeness in courtroom discourse on the part of the weak may in fact be a subtle mechanism for linguistic coercion.

Some pragmatic strategies are person targeted by diminishing the credibility of the witness often referred to as a 'social degradation ceremony' and courts have been portrayed as the perfect stage for acting out such status degradation in our societies (Coulthard, 2001). Witness character may be attacked rather than the content of his testimony typically status manipulation through status reduction. In conclusion, the specialist and power laden legal language (high register) is different in four critical areas with everyday conversational language which is contextualized, informal, non-specialist and low in power differences. It is apparent that relationship between people in the legal context is constructed through language perpetuated through differential control of knowledge and expertise via language. Language is a powerful weapon in the legal process and for the socially weak, there is little hope for balanced justice where pursuit for proof is not counterbalanced by pursuit for truth that may often be found only in one's mother tongue.

Disadvantage caused by poor mastery of high register is made worse by the adversarial nature of examination in the Kenyan courts. Cross-examination typically is meant to subject both the witness and the evidence to test. Functionally illiterate Kenyans happen to be the majority and seem to be over-represented among the accused. They are less articulate, educated and confident but examination is a linguistic process that requires these key features. Attitudinal elements come into play where differences in languages are perceived as cultural and ethnic differences that may lead directly into social attitudes and prejudices. Such a population is often not confident and may be interpreted as guilty (Gibbons, 2005) and will hardly receive justice (Tiersma \& Solan, 2002:229). The Kenyan judicial process may be a mechanism for oppression and persecution instead of guaranteeing justice. A second language speaker, who does not speak English without interpreting service, faces injustice for neither understanding the proceedings nor making a case. Studies have shown that courtroom comprehension difficulties are largely linguistic and not due other factors (Gibbons, 1994, 2005; Tiersma, 2001; Tiersma \& Solan, 2002, among others).

In matters sexual abuse, the victim is frightened into silence largely due to some linguistic taboos. Disadvantage suffered by uneducated Kenyans in contact with law are many due to 'knowledge economy' in which silence is preferred because information sought is of privileged status available only to the initiated and via a genre only possible in the mother tongue. In some Kenyan communities, one cannot state the number of children he has or property such as cows or even the years he has lived. However, our court trials are premised on the right to question by the prosecutor and the obligation to answer on the part of the questioned. In Common Law, silence is not an option in spite of the highly coercive and humiliating person-oriented status reduction form of questioning by 'owners of the linguistic power'; the prosecutors, counsels and judges.

There are obvious differences between Standard English and localized Kenyan English such that some Kenyans in the courtroom are more likely to be 'gratuitous' in saying 'yes' to every question simply to avoid further pressure or questioning by the overbearing lawyer or policeman. Expectedly, the consequences may be grave depending on the crime for which they are accused; a miscarriage of justice. For second language speakers, this is true of majority of Kenyans, this is the case in the context of English as the language of the courts. Indicators of miscommunication are many; overt statements of incomprehension (initiated repair moves), asking what to say, responding with apologies, (sorry, I beg your pardon), clarification requests, absence or inappropriate responses, not to mention others. When interviewing in English, there are substantial problems of communication that is a distortion of due process in legal terms. All information in the courts and prisons are in English and similarly with all records including evidence. Most prisoners/suspects, though able to communicate orally, have difficulties dealing with official documents that are in the Standard legal English full of legalese terminologies.

For the deaf community, sign language is their mother tongue. The deaf are a special case of second language speakers only that they cannot develop full speech; can never have full and equal access to spoken 
language. The deaf are mainly non-literate because writing system for signed language is only emerging in the country. Linguistic barrier between the deaf and the predominantly hearing group is substantial. Even with sign interpreters available, there are no signs for certain legal terminologies because there is no signed legal system. A low level of literacy makes it hard for the deaf to master the written register of the documents of the courts. Sign language lack most legal honorifics and markers of power relations such as 'Your honour' hence signed testimony of the deaf may look disrespectful. In other words, most characteristics of the legal language such as technicality, writtenness and power, will pose communication difficulties for deaf in legal contexts. As observed by Gibbons (2005), a signer who is handcuffed is virtually gagged, one restrained may be misinterpreted as 'struggling' when trying to sign and in the absence of other deaf prisoners; they are in virtual solitary confinement.

Social class has a bearing on language and hence disadvantage before the law. There are language implications of the different social class and the degree to which work demands or involves the use of High Register or not. There is a covert relationship between the social class, level of education and command of High Register of legal English. In the Kenyan context, people from the informal unskilled sector, have low command of Standard English. They will have difficulty in understanding legal process and putting across their version of the case/event. Social stereotyping arising from their limited command of legal register contributes to unequal treatment in the justice system. Law enforcers typically attribute anti-social and criminal behaviour to youths from slums/ghettos and low working class viewing them as being in a 'punishment frame' but a 'depressed state' to youths from the middle-high class suburbs. The latter may be given a second chance but not the former. Judges' social prejudices may be activated by such differences becoming actors in status support for the privileged youth. Youths from the slums have their 'Sheng' as their mother language, yet its usage only leads to prejudice.

Cases involving abused women in sexual assault indicate that linguistic power asymmetry manifested in the justice system is an avenue for propagation of injustice. Typically, the style in cross-examination makes it impossible for them to argue their case when the legal language is simply incomprehensible and full of taboo words. Interruptions, taking away their turn, casting doubt on witness credibility, use of coercive question forms, and topic/ information control via calculated legal language, are common strategies. Lawyers construct a version of the assault in which the victim is portrayed as a willing participant, alcoholic, drug addict and promiscuous. A woman's previous sexual experience may be asked as a means to portray her as unreliable, raise social prejudice against her, traumatize and humiliate her to defeat justice. Ultimately the aim is to upset her, ensure she is seen negatively once she refuses to cooperate. If mother language is allowed, it may be a mitigating factor for victims of rape, among other litigants.

In a nutshell, language use in the justice system is geared to disadvantage those who are socially marginalized and less powerful from the point of view of legal language mastery. This is a group with limited linguistic resources and faced with the linguistically privileged judicial and legal officers, there is little room for justice for such a group. The justice system is structured in a manner that ensures those who wield power over language of the legal practice have their way. Redress is urgent for the lay audience seeking justice. Provisions that guarantee equal status to local mother languages is the way to go to mitigate the trauma suffered by poor Kenyans when confronted by an overbearing legalese system similar to one practiced in the Kenyan judiciary.

\section{Seeking Redress: The Way Forward}

There is a clear mismatch between constitutional provisions and legislation on one hand, and the justice system on the other in regard to Kenyans' right to their mother tongue. It is imperative that a solution is sought to address the injustice suffered by Kenyans in the justice system. An area that requires immediate attention is constitutional review to make it mandatory for courts to allow litigants to use a language of their choice especially lay defendants with no knowledge of the legal English. Article 19 (3c) should make it explicit that there is no limitation to a person's right to use the mother tongue in judicial/legal process due to the legalistic nature of legal English language. Related to this amendment is the need for the UN General Assembly to officially adopt the Universal Declaration of Linguistic Rights (The Barcelona Declaration) of 1996. Member countries such as Kenya, would then be required, upon signing the Declaration, to fully implement the letter and spirit of the Barcelona declaration in promoting mother tongue usage besides its unequivocal protection.

In the application of the Bill of Rights (BR), Article 20 should be repealed to read that its application binds all state organs and persons and that it is criminal to deny any Kenyan the right to use mother tongue. In enforcement of the BR, the courts under Article 27 (4) should declare any denial of mother tongue to a person as unconstitutional. Similarly, lack of resources for its full implementation under Article 21 cannot be a limitation to the enjoyment of this right and that Article 24 (1a) is not applicable to mother language; no law can be constitutional if it denies mother language to those seeking justice in our courts. In other words, the right to mother tongue should be included in Article 25 which stipulates which fundamental rights and freedom that cannot be limited by legislative law. Recognition of sign language (De Meulder, 2015) is a key factor in this 
amendment in which the deaf community should have their sign language given both constitution and legal formal status and rights. Most injustice suffered by Kenyans is due to miscommunication or the incomprehensible legal language.

Legal reform should focus on bridging this gap by adopting the 'plain language' concept in legal drafting and general judicial proceedings. This may solve the 'two audience dilemma' of the legal language so long as the main aim of 'precision and unambiguous interpretation' of legal documents and statutes is not compromised. Sources of miscommunication are mainly linguistic or cultural, it is imperative that training in this area is instituted for the police, the bar, the bench and the general public similar to countries such as Canada, Australia, USA, among others (Gibbons 2005:229; Tiersma \& Solan, 2002). Mediation and advocacy by experts who understand the bilateral divide could be used as another option. In Kenya, there could be a Kikuyu Legal Services that has people with expertise in the culture and law of Agikuyu or Agikuyu court liaison officers to handle issues that emerge when the lay Agikuyu, for instance, comes into contact with judicial administrators in and out of court.

Similarly, it is critical to reform the legal process that is currently too alien, incomprehensible and overly horrifying to Kenyans of different cultures. This may include rules that guarantee the presence of an advocate or a 'friend' to the accused with legal knowledge during interrogations and statement recording to avoid gratuitous concurrences. Furthermore, guidelines on question formulation by advocates and police interrogators are required to ensure comprehension by the accused and witnesses. Related issue concerns guidelines for judges to control and prevent leading or culturally insensitive questioning that disregards one's mother tongue and culture. The courts and the judicial system should develop a legal interpretation and translation division to provide access to Kenyans who are not competent in the legal English. Kenyans with no knowledge of the legal language must be guaranteed an interpreter or a translator for free to participate fully in the judicial process. There is need for legal framework in the provision of such services that must also be professionalized with appropriate certification.

Kenya as a signatory to 'The International Covenant-Civil and Political Rights' should enforce article 14 (3) of the international convention on human rights which states, among other things, that; 'In determination of any criminal judge against him, every one shall be entitled to the following minimum guarantees, in full equality:

(a) To be informed promptly and in detail in a language which he understands of the nature and cause of the charge against him; ...

(f) To have the free assistance of an interpreter if he cannot understand or speak the language used in the court.

In essence the police and the courts have an obligation under the provisions in (a) while (f) may be relevant to proceedings in the courts and is interpreted as meaning 'completely and unconditionally free'. The same should apply to the committal hearings including documents that are pertinent to the case. The current Common Law practice in Kenya based on the doctrine that 'there is no right to an interpreter but one may be provided at the discretion of the judge/magistrate or court officer' must be amended. To make this process meaningful, there is need for 'Interpreter Education' alongside translation certification to ensure there are enough competent and qualified personnel to offer such services. Such personnel must be proficient in both languages besides their regional variants, possess good general knowledge and that of professional ethics, legal language and process and the discourse conventions of the courtroom and police. Professionalization of legal interpretation is, therefore, a major requirement in the entire reform process which may also target lawyers and other legal professionals in the Kenyan judicial system to make them more open to mother tongue use and people's right to its usage.

Finally, forensic linguists as expert witness should be allowed in our judicial system in view of the fact that misunderstanding in the justice system are largely linguistic in nature. In addition, linguistic issues tend to arise in virtually all legal contexts in the judicial system as a whole. Forensic linguists could provide necessary evidence in areas where their expertise is critical such as testifying on cases involving probable origin of a speaker (anonymous hate speech), the comprehensibility of legal text, whether specific defendant understood the 'Miranda' warning and the phonetic similarity of two competing trademarks in dispute. Similarly, forensic linguists may be useful in issues concerning the likelihood of confusion in trademark cases, miscommunication due to dialectal differences, the meanings of statutes, wills and contracts, code deciphering, plagiarism and the identification of authors and speakers (author attribution) in criminal cases. Practically, any area of linguistics is relevant and valuable in the administration of justice in our courts right from phonetics to pragmatics and there is need for formal legal recognition of forensic linguistic expertise.

\section{Conclusion}

It is evident that a lot of injustice is committed when Kenyans who seek justice or take part in the judicial process are denied the right to use or to be addressed in their mother language. The right to one's mother tongue cannot be a simple legislative issue; it is at the core of every Kenyan's humanity as a human right, an inalienable 
right not subject to debate. It is, therefore, of paramount necessity for all state players and individual Kenyans to ensure that this right is observed and respected especially in our justice system; the custodian of justice for Kenyans. While there might be challenges in according all Kenyans the right to their mother language, it is not beyond attainment. The right to mother tongue is a constitutional provision which all state organs and agents have an obligation to protect and enforce unreservedly. It is only when all Kenyans have access to justice through their mother tongue; a language they understand, that the essence of celebrating International Mother Language Day will be fully realized.

\section{Acknowledgement}

The initial unpublished PowerPoint version of this paper was presented at the International Mother Language Day Conference on $22^{\text {nd }}$ February, 2019 at Kenyatta University, Kenya. I appreciate the participants whose comments have gone into improving this paper.

\section{References}

Bhatia, V. K. (1993). Analysing Genre: Language Use in Professional Setting. Harlow: Longman Publishers.

Coulthard, M. (2001). Power and Control in the Representation of Evidence. Paper presented at Discourse conference, University of Technology, Sydney.

Coulthard, M., \& Johnson, A. (2010). The Routledge Handbook of Forensic Linguistics. New York: Routledge.

Coulthard, M., Johnson A. (2007). An Introduction to Forensic Linguistics: Language in Evidence. London: Routledge

Coulthard, M., A. Johnson \& Wright, D. (2016). An Introduction to Forensic Linguistics: Language in Evidence. London: Routledge.

De Groot, G. \& van Laer, C. J. P. (2006). The Dubious Quality of Legal Dictionaries. International Journal of Legal Information, 34 (1), 64-86.

De Meulder, M. (2015). The Legal Recognition of Sign Languages. Sing Language Studies, 15 (4), $498-506$.

Dickens, C. (1893). Bleak House. London: Chapman and Hall.

Gibbons, J. (1994). (Ed.). Language and the Law. Harlow: Longman Publishers.

Gibbons, J. (2005). Forensic Linguistics: An Introduction to Language in the Justice System. Malden MA.

Blackwell Publishers.

Goodrich, P. (1987). Legal Discourse. London: Macmillan Press.

Gowers, E. (1948). Plain Words. London: Her Majesty's Stationery Office.

Halliday, M. A. K. (1985). Spoken and written Language. Geelong, Victoria: Deakin University Press.

Jackson, B. (1990). Semiotics and the Problem of Interpretation. In P. Nerholt (Ed.), Law Interpretation and Reality.

Dordrecht: Kluwer, pp. 84-103.

Jacquemet, M. (1996). Credibility in Court: Communicative Practices in Camorra Trials. Cambridge: Cambridge

University Press.

Maley, Y. (1994). The Language of the Law. In J. Gibbons, (Ed.) Language and the Law. Harlow: Longman Publishers, pp. 3-50.

Mattila, E. S. H. (2016). Comparative Legal Linguistics. London: Ashgate Publishing.

Mellinkoff, D. (1963). Language of the Law. Boston, MA: Little Brown Publishers.

National Council for Law Reporting. (2013). The Constitution of Kenya, 2010. Kenya Law Reports. Nairobi:

Government Press. Retrieved from www.kenyalaw.org

Olsson, J. (2018). More Wordcrime: Solving crime with Linguistics. London: Continuum.

Renton, D. (1975). The Preparation of Legislation: Report of a Committee Appointed by the Lord President of the Council. London: Her Majesty's Stationery Office.

Shuy, R. W. (2005). Creating Language Crime. New York: Oxford: Oxford University Press.

Shuy, R. W. (2006). Linguistics in the Courtroom: A Practical Guide. Oxford: Oxford University Press.

Stygall, G. (1994). Trial Language: Differential Discourse Processing and Discursive Formation. Amsterdam: John

Benjamins.

Tiersma, P. M. (1999). Legal Language. Chicago: Chicago University Press.

Tiersma, P. (2001). Textualising the Law. Forensic Linguistics, 8(2), 73-92.

Tersma, P. \& Solan, L. M. (2002). The Linguist on the Witness Stand: Forensic Linguistics in American Courts. Language 78 (2), 221-239. 